\title{
ЭКОЛОГИЧЕСКИ ОРИЕНТИРОВАННАЯ ВНЕУРОЧНАЯ ДЕЯТЕЛЬНОСТЬ В ШКОЛЕ: ИННОВАЦИИ И РЕЗУЛЬТАТЫ
}

\author{
Гущцна Э.В.
}

Тихоокерситетабаровск, Российская Федерация

Санкт-Петербургская академия постдипломного педагогического образования, г. Санкт-Петербург, Российская Федераџия

В статье приведены результаты исследования экологически ориентированной внеурочной деятельности в школах СанктПетербурга: определень признаки инновационности внеурочной деятельности; дан анализ компонентов экологической культуры, на формирование которых в большей степени влияет внеурочная деятельность; приведены преобладаюшие образовательные технологии и формы организации внеурочной деятельности.

Ключевые слова: экологическое образование; внеурочная деятельность; экологическая культура; педагогические инновации; интерактивные образовательные технологии.

\section{ECOLOGICALLY ORIENTED EXTRACURRICULAR ACTIVITIES IN SCHOOL: INNOVATION AND RESULTS}

\section{Gushchina E.V.}

Saint-Petersburg academy of post-degree pedagogical education, Saint-Petersburg, Russian Federation

The article presents the results of a study of environmentally-oriented extracurricular activities in schools of St. Petersburg: the signs of innovativeness of extracurricular activities are identified; an analysis of the components of ecological culture, the formation of which is largely 
influenced by extracurricular activities; the prevailing educational technologies and forms of organization of extracurricular activities are given.

Keywords: environmental education; extracurricular activities; ecological culture; pedagogical innovations; interactive educational technologies.

\section{Введение}

В ФГОС начального и основного общего образования базовые экологические ценности и знания не локализованы в рамках одного учебного предмета, а пронизывают все учебное содержание. Однако рамки уроков ограничивают возможности экологической социализации школьников. Включению детей в процесс активного усвоения социально-экологического опыта, освоению культурной и социальной практики способствует процесс интеграции урочной и экологически ориентированной внеурочной деятельности на основе системно-деятельностного подхода [2].

\section{Материалы и методы исследования}

Кафедрой педагогики окружающей среды, безопасности и здоровья человека Санкт-Петербургской академии постдипломного педагогического образования (С.В. Алексеев, Э.В. Гущина, Л.И. Гущина, Т.А. Шиленок) проведено исследование инновационных форм организации внеурочной деятельности по формированию экологической культуры учащихся начальной и основной школы. В анкетном опросе приняли участие 37 общеобразовательных учреждений (OУ) из 16 районов Санкт-Петербурга [1].

\section{Результаты исследования и обсуждение}

В ходе исследования определен рейтинг признаков инновационности во внеурочной деятельности. Инновационный характер внеурочной деятельности определяется, в первую очередь, прогностическим характером (82,8\%), новыми подходами, формами, характером организации взаимодействия обучающихся и педагогов на основе взаимодействия, творчества, взаимного учета интересов 
(79,3\%). Поиск ресурсов инноваций в основном осуществляется внутри образовательной системы $(69,0 \%)$, и может основываться как на принципиально новых идеях и подходах $(65,5 \%)$, так и на новом сочетании известных элементов (62,1\%). 51,7\% ОУ уделяют внимание в инновационной деятельности подготовке педагогических кадров, научно-методическому и материальному обеспечению.

В целом инновации во внеурочной деятельности востребованы образовательной практикой $(55,0 \%)$, направлены на обновление существенных элементов системы в соответствии с новыми задачами (44,8\%). К проблемам в понимании инновационного характера внеурочной деятельности следует отнести то, что стабильность результатов при повторном использовании указали лишь в 17,2\% общеобразовательных организаций.

Анализ компонентов экологической культуры, на формирование которых в большей степени влияет внеурочная деятельность, показал, что в целом педагоги ОУ, принявших участие в исследовании, осознают особенности и воспитательную направленность экологической внеурочной деятельности, выделяя, в первую очередь, ценностно-мотивационную сферу $(86,2 \%)$ и формирование экологического сознания детей $(84,5 \%)$. Существенное внимание обращается на экологические знания (79,3\%). Однако явно недостаточное внимание уделяется рефлексивной деятельности обучающихся $(20,7 \%)$ - осмыслению событий, способов и следствий взаимодействия с природой и окружающей средой в целом, оценке своих действия в повседневной жизни с точки зрения их экологической целесообразности.

Важнейший инновационный ресурс экологического образования - использование интерактивных образовательных технологий. Интерактивное взаимодействие трактуется как усиленная деятельность между кем-либо, как обучение, построенное на взаимодействии обучающегося с учебным окружением, образовательной средой [3].

Во внеурочной деятельности преобладают образовательные технологии, позволяющие использовать помимо класса другие ресурсы 
образовательной среды - пришкольную территорию в целом $(75,9 \%)$, экологическую тропу $(27,6 \%)$, рекреации $(27,6 \%)$, спортивный и актовый залы и пр. Наиболее активно используются игровые технологии (82,8\%), а также проектная внеурочная деятельность (79,3\%). Эколого-образовательные проекты - одна из ведущих личностно ориентированных технологий.

В различных видах внеурочной деятельности активно используются информационно-компьютерные технологии (34,5\%), однако педагоги рассматривают их как один из инструментов, а не как ведущий вид деятельности.

Практически все ОУ (96,6\%) отметили, что проектная деятельность носит межпредметный и надпредметный характер. Также во внеурочной деятельности активно используются кейс-метод $(31,0 \%)$, конференции и семинары (27,6\%), практикумы (20,7\%).

Основные формы организации экологически ориентированной внеурочной деятельности, отмеченные ОУ, следующие: детские объединения (кружки, клубы и пр.) (86,2\%); реализация различных проектов (86,2\%); общественно-полезная практика $(44,8 \%)$; научное общество (37,9\%). Среди других организационных форм во внеурочной деятельности используются экологические экспедиции, каникулярная школа, экологическая агитбригада, массовые мероприятия и акции, тьюторское движение, деятельность экологических советов и др.

Исследовательская внеурочная экологическая деятельность различается:

- по содержанию: мониторинг различных природных сред (атмосферы, гидросферы, педосферы) (62,1\%); оценка экологического состояния культурных объектов, территорий, социально-экологических аспектов и др. (58,2\%);

- по используемым методам: реферативные методы (описательные) $(79,3 \%)$; инструментальные методы $(55,2 \%)$; полевые исследования (44,8\%); модельные эксперименты (24,1\%);

- по использованию полученных результатов: используются при подготовке олимпиадных работ $(82,8 \%)$; публикуются в 
школьной печати (48,3\%); представляются на конференциях, круглых столах и пр. $(27,6 \%)$; отсылаются в районные экологические службы $(27,6 \%)$.

\section{Заключение}

Анализ представленных результатов позволяет сделать вывод, что именно во внеурочной деятельности в большей степени может быть реализовано эффективное сочетание различных интерактивных образовательных технологий - игровых, поисковых, исследовательских, презентационных, рефлексивных и пр., а также форм деятельности, обеспечивающих не только развитие исследовательских умений учащихся, но и их экологическую социализацию как составляющих экологической культуры школьников в открытой образовательной среде.

Информация о конфликте интересов. Автор заявляет об отсутствии конфликта интересов.

Информация о спонсорстве. Исследование не имело спонсорской поддержки.

\section{Список литературы}

1. Гущина Э.В. Инновационные формы организации внеурочной деятельности по формированию экологической культуры: результаты исследования в Санкт-Петербурге // Лучшие практики экологического образования в интересах устойчивого развития: монография / под. общ. ред. С.В. Алексеева, А.Н. Захлебного. СПб.: СПб АППО, 2018. 208 с. (Научные школы академии).

2. Информация об инновационном продукте: Экологический календарь для младших школьников / Гущина Э.В. и др. [Электронный pecypc]. Режим доступа: https://school71.spb.ru/files/oer/innovation. pdf

3. Кашлев С.С. Интерактивные методы развития экологической культуры учащихся: Пособие для педагогов. Мн.: Зорны верасень, 2007. 


\section{References}

1. Gushchina E.V. Innovatsionnyye formy organizatsii vneurochnoy deyatelnosti po formirovaniyu ekologicheskoy kultury: rezultaty issledovaniya v Sankt-Peterburge // Luchshiye praktiki ekologicheskogo obrazovaniya $\mathrm{v}$ interesakh ustoychivogo razvitiya: monografiya [Innovative forms of organization of extracurricular activities on the formation of environmental culture: results of research in St. Petersburg // Best practices of environmental education for sustainable development: monograph] / pod. obshch. red. S.V. Alekseyeva. A.N. Zakhlebnogo. SPb.: SPb APPO. 2018. 208 s. (Nauchnyye shkoly akademii).

2. Informatsiya ob innovatsionnom produkte: Ekologicheskiy kalendar dlya mladshikh shkolnikov [Information on an innovative product: Ecological calendar for younger students] / Gushchina E.V. i dr. [Elektronnyy resurs]. Rezhim dostupa: https://school71.spb.ru/files/oer/innovation.pdf

3. Kashlev S.S. Interaktivnyye metody razvitiya ekologicheskoy kultury uchashchikhsya: Posobiye dlya pedagogov. [Interactive methods for the development of students' ecological culture: A manual for teachers]. Mn.: Zorny verasen. 2007. 